\title{
Rancang Bangun Sistem Distribusi Gas LPG 3 Kg Menggunakan RFID Pada E-KTP
}

\author{
Hasanah Nusa An-Nafi ${ }^{1}$, Onki Alexander ${ }^{2}$ \\ ${ }^{1,2}$ Politeknik Negeri Jakarta \\ email: hasanah.nusaannafi.tik17@mhsw.pnj.ac.id, onki@jgu.ac.id,
}

\begin{abstract}
The management of distribution of $3 \mathrm{Kg} L P G$ gas to the poor is not evenly distributed. Some of the contributing factors are the low price of $3 \mathrm{Kg}$ gas so that its distribution exceeds the recommended quota. This results in the price and amount of distribution being unbalanced to the distribution by region. The purpose of this study is to design a $3 \mathrm{Kg} L P G$ gas distribution system using Radio Frequency Identification (RFID) on a web-based E-KTP to facilitate transactions for $3 \mathrm{Kg} L P G$ gas and prevent the accumulation of 3 $\mathrm{Kg}$ LPG gas. Using a quantitative study research method, namely an experimental study that aims to collect information about the problem, this study also uses the Waterfall Model System Development Life Cycle (SDLC) method, which is a method that uses analysis, design, coding, testing, and supporting techniques. The result of this research is an application to manage sales of subsidized $3 \mathrm{Kg} L P G$ gas so that there is no stockpiling at a base that causes an imbalance in distribution.
\end{abstract}

Keywords: Development, SDLC, Disribution, E-KTP, RFID Reader

\begin{abstract}
Abstrak: Pengelolaan distribusi gas LPG 3 Kg pada masyarakat miskin tidak merata. Beberapa faktor penyebabnya yaitu harga gas LPG $3 \mathrm{Kg}$ yang murah sehingga distribusi melebihi jatah yang disarankan. Hal tersebut mengakibatkan harga dan jumlah distribusi tidak seimbang terhadap distribusi perwilayah. Tujuan penelitian ini adalah merancang bangun sistem distribusi gas LPG $3 \mathrm{Kg}$ menggunakan Radio Frequency Identification (RFID) pada E-KTP berbasis web untuk memudahkan dalam melakukan transaksi gas LPG $3 \mathrm{Kg}$ dan mencegah terjadinya penimbunan gas LPG $3 \mathrm{Kg}$. Menggunakan metode penelitian studi kuantitatif yaitu studi experimental yang bertujuan untuk mengumpulkan informasi seputar permasalahan, penelitian ini juga menggunakan metode System Development Life Cycle (SDLC) model Waterfall, yaitu metode yang menggunakan teknik analisis, desain, pengodean, pengujian, dan pendukung. Hasil penelitian ini adalah suatu aplikasi untuk memanajemen penjualan gas LPG $3 \mathrm{Kg}$ bersubsidi agar tidak terjadinya penimbunan disuatu pangkalan yang menyebabkan ketidak seimbangan terhadap distribusi.
\end{abstract}

Kata kunci: Development, SDLC, Distribusi, E-KTP, RFID Reader

\section{Pendahuluan}

Pada saat ini masyarakat Indonesia sudah menggunakan E-KTP yang terdapat chip Radio Frequency Identification (RFID) namun untuk pemanfaatanya masih kurang. E-KTP saat ini hanya digunakan untuk pengurusan izin dan sebagai tanda pengenal atau tanda penduduk warga Indonesia. Sedangkan E-KTP memiliki fitur chip RFID yang masih kurang untuk pemanfaatan dari segi fitur pada E-KTP. Fitur pada E-KTP dapat digunakan sebagai RFID tag karena didalamanya terdapat chip yang menyimpan nomor ID unik (Mahesa et al., 2019). Sehingga RFID dapat dijadikan salah satu teknologi yang dapat dimanfaatkan. Dikutip oleh pertamina LPG $3 \mathrm{Kg}$ merupakan Liquefied Petroleum Gas yang selanjutnya disebut LPG adalah gas hidrokarbon yang dicairkan dengan tekanan untuk memudahkan penyimpanan, pengangkutan dan penanganannya yang pada dasarnya terdiri atas propane, butana, atau campuran keduanya (Pertamina, 2020). Menurut data responden dari 101 orang 80,2\% adalah pengguna LPG $3 \mathrm{Kg}$ dan dari 101 orang responden 52,5\% mengalami kelangkaan gas LPG $3 \mathrm{Kg}$, 
sehingga dapat di simpulkan bahwa banyak masyarakat pengguna LPG $3 \mathrm{Kg}$ yang pernah mengalami kelangkaan stock gas LPG $3 \mathrm{Kg}$.

Pada saat ini pengelolaan distribusi gas LPG $3 \mathrm{Kg}$ pada masyarakat miskin tidak merata. Beberapa faktor penyebabnya yaitu harga gas LPG $3 \mathrm{Kg}$ yang murah sehingga distribusi melebihi jatah yang disarankan. Hal tersebut mengakibatkan harga dan jumlah distribusi tidak seimbang terhadap distribusi perwilayah serta menciptakan harga yang relative tinggi disbanding HET konsumen akhir. Seperti yang terdapat pada data berita yang dikutip oleh CNBC Indonesia dimana konsumsi LPG dalam negeri terus mencatatkan pertumbuhan. Pada tahun 2016-2017 konsumsi tumbuh 4,8\%, tahun 20172018 volumenya naik 3,8\% dan tahun 2018-2019 jumlahnya kembali naik 4,8\%. Untuk LPG ukuran $3 \mathrm{Kg}$, pemerintah menganggarkan subsidi untuk masyarakat dengan daya beli rendah agar mampu membeli LPG melon untuk kebutuhan sehari-hari, pada tahun 2017 kuota subsidi LPG mencapai 6,2 juta metrik ton. Pada 2018 kuotaya naik menjadi 6,53 juta metrik ton. Terakhir tahun lalu, kuota subsidi juga naik lagi menjadi 6,97 juta metrik ton. Sepanjang tahun 2019 pemerintah telah mengeluarkan subsidi untuk LPG melon sebesar Rp. 42,47 triliun. Beban pemerintah untuk memberikan subsidi jadi meningkat, karena volume konsumsinya terus meningkat. Beban juga meningkat karena dua faktor lain. Pertama subsidi yang tidak tepat sasaran. Artinya LPG $3 \mathrm{Kg}$ tidak hanya dibeli oleh kalangan tak mampu saja tetapi juga dibeli kalangan yang tergolong mampu (CNBC Indonesia, 2020).

Pemanfaatan aplikasi ini
merupakan aplikasi berbasis web
dengan framework CI (CodeIgniter)
untuk merancang sistem monitoring
distribusi gas LPG $3 \mathrm{Kg}$ menggunakan
Radio Frequency Identification (RFID)

pada E-KTP. Menggunakan metode penelitian deskriptif yang bertujuan untuk mengumpulkan informasi seputar permasalahan. Penelitian ini juga menggunakan metode System Development Life Cycle (SDLC) model waterfall, yaitu metode yang memiliki tahapan analisis, desain, pengodean, pengujian, pendukung. Hasil penelitian ini adalah suatu aplikasi untuk memanajemen penjualan gas LPG $3 \mathrm{Kg}$ bersubsidi agar tidak terjadinya penimbunan disuatu pangkalan yang mengakibatkan harga melebihi HET konsumen akhir yang telah ditetapkan.

\section{Metode}

Penelitian ini menggunakan metode SDLC model waterfall. Ada beberapa tahap yang dilakukan untuk merealisasikan pembuatan sistem pada penelitian ini, sebagai berikut: (Juniardi Dermawan, 2017).

1. Analisa Kebutuhan

Tahap analisis, dimulai dengan menganalisis data hasil permasalahan yang ada. Pada tahap ini, sistem akan dianalisis bagaimana sistem akan dijalankan nantinya. Hasil pada tahapan analisis ini berupa kelebihan dan kekurangan sistem, fungsi sistem, hingga pembaruan yang dapat diterapkan pada sistem berbasis web mengenai distribusi gas LPG $3 \mathrm{Kg}$ menggunakan Radio Frequency Identification (RFID) pada E-KTP.

Dalam menganalisa kebutuhan user (pengguna), dilakukan wawancara terhadap agen, pangkalan, dan penyebaran kuisioner. Wawancara dilakukan dengan agen PT. CAHAYA INTI GASINDO JAYA. Sedangkan penyebaran kuisioner ditujukan untuk ibu rumah tangga atau pengguna tabung gas LPG $3 \mathrm{Kg}$.

Berdasarkan wawancara dan penyebaran kuisioner yang telah dilakukan, dapat diketahui kebutuhan fungsional dan non fungsional sistem yang dapat diuraikan sebagai berikut:

a. Kebutuhan Fungsional

- Agen dapat mengetahui informasi-informasi pangkalan 
yang melakukan pembelian pada agen dan membuatkan akun untuk pangkalan tersebut.

- Agen dapat memonitoring distribusi gas LPG $3 \mathrm{Kg}$ yang dilakukan oleh pangklanpangkalan yang terdaftar di agen.

- Agen dapat mencatat setiap pembelian gas LPG $3 \mathrm{Kg}$ yang dilakukan oleh pangkalan yang telah terdaftar.

- Agen dapat mencetak laporan pencatatan pembelian gas LPG 3 Kg yang dilakukan oleh pangkalan yang telah terdaftar per bulan.

- Pangkalan dapat menambahkan data pelanggan dengan cara mentapping E-KTP.

- Pangkalan dapat mencatat jumlah distribusi gas LPG $3 \mathrm{Kg}$ ke pelanggan dengan cara mentapping E-KTP.

- Pangkalan dapat membatasi pembelian pelanggan sebanyak empat kali per bulan untuk gas LPG $3 \mathrm{Kg}$ yang bersubsidi per individu serta mengirimkan notifikasi melalui email pelanggan.

b. Kebutuhan Fungsional

Sistem monitoring distribusi gas LPG $3 \mathrm{Kg}$ bersubsidi berjalan pada web. Pengembangan menggunakan Framework CodeIgniter. Sistem monitoring distribusi ini diimplementasikan dengan alat RFID Reader.

2. Cara Kerja Program Aplikasi

Untuk menggambarkan cara kerja program sistem digunakan flowchart sistem secara keseluruhan. Adapun flowchart dan penjelasannya sebagai berikut:

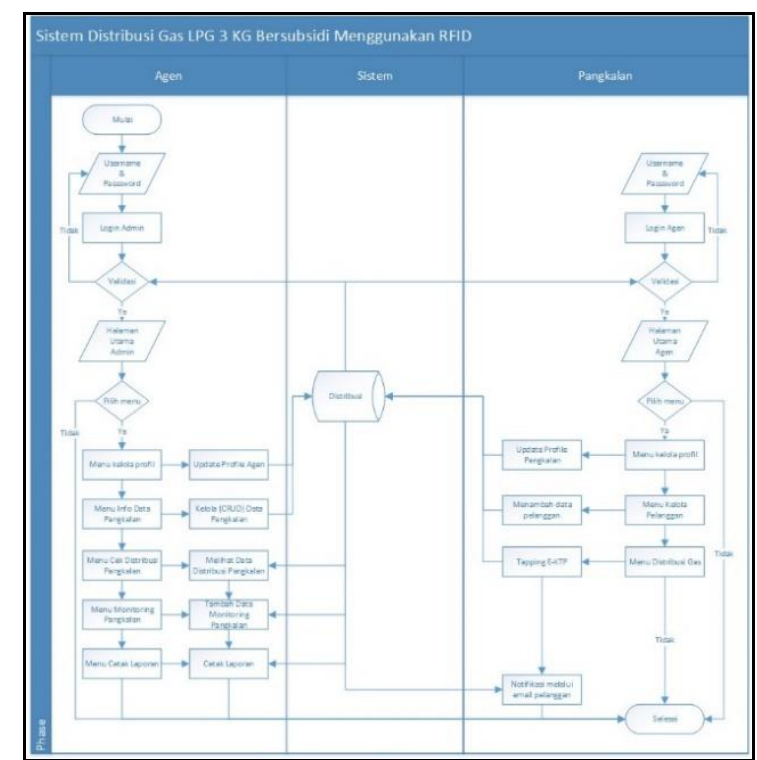

Gambar 1. Flowchart sistem distribusi gas LPG $3 \mathrm{Kg}$ (keseluruhan)

Gambar 1 merupakan gambar alur dari aplikasi sistem disribusi gs LPG $3 \mathrm{Kg}$ menggunakan RFID pada EKTP berbasis web. Dimulai dengan login yang dilakukan oleh masingmasing level user yang telah diberikan untuk agen dan pangkalan. Jika agen berhasil login maka akan tampil halaman utama atau yang disebut dengan dashboard. Setelah muncul halaman dashboard agen dapat memilih menu data info pangkalan, menu cek distribusi pangkalan, menu monitoring pangkalan, menu cetak laporan, dan menu kelola profile agen.

$$
\text { Sedangkan untuk level }
$$
pangkalan setelah berhasil login sesuai dengan username dan password yang dibuatkan oleh agen, maka pangkalan dapat melihat halaman utama pangkalan atau dashboard. Setelah itu pangkalan dapat memilih menu Kelola profile, menu Kelola pelanggan, dan menu distribusi gas.

Tapping E-KTP ke RFID Reader dilakukan pada menu Kelola pelanggan dan menu distribusi gas. Digunakan pada saat pelanggan mendaftarkan diri sebagai penerima pada pangkalan tersebut dan saat melakukan pendistribusian yang dilakukan oleh pangkalan ke masyarakat miskin. Apabila 
masyarakat miskin telah terdaftar pada salah satu pangkalan, masyarakat miskin tidak dapat mendaftarkan dirinya lagi di pangkalan lain. Selain itu diberlakukannya pembatasan pembelian yang dapat dilakukan oleh pelanggan sebanyak 4 kali dalam sebulan, setiap pengambilan yang dilakukan oleh pelanggan akan dikirimkan notifikasi sisa tabung yang dapat diambil dan jumlah tabung yang telah dibeli pelanggan melalui email yang sudah terdaftar pada system.

\section{Rancangan Program}

Rancangan Program sistem distribusi gas LPG $3 \mathrm{Kg}$ menggunakan RFID pada E-KTP ini dengan menggunakan Use Case Diagram.

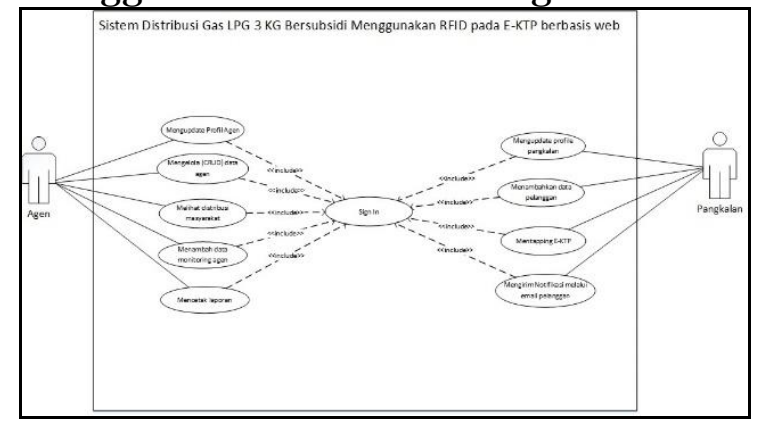

Gambar 2. Use case diagram sistem distribusi gas LPG $3 \mathrm{Kg}$

Gambar 2 merupakan use case diagram untuk sistem distribusi gas LPG 3 Kg menggunakan RFID pada EKTP, dimana pada sistem ini melibatkan dua aktor, yaitu agen dan pangkalan. Pre-Process pada use case diagram ini semua user telah login ke dalam sistem. Berikut ini penjelasan dari use case diagram diatas:

a. Agen adalah aktor yang dapat mengupdate profil agen.

b. Agen adalah aktor yang dapat mengelola data pangkalan seperti menambah data pangkalan, update data pangkalan, dan delete data pangkalan.

c. Agen dapat melihat data distribusi masyarakat.

d. Agen dapat menambah data monitoring pangkalan. e. Agen dapat mencetak laporan data monitoring pangkalan dalam kurun waktu satu bulan.

f. Pangkalan adalah aktor yang dapat mengelola profile pangkalan seperti mengupdate data pangkalan tersebut.

g. Pangkalan dapat menambahkan data pelanggan yang mendapatkan subsidi $3 \mathrm{Kg}$.

h. Pangkalan dapat mengirimkan notifikasi sisa pembelian tabung yang dapat dilakukan pelanggan melalui email.

i. Pangkalan dapat mengirimkan notifikasi sisa pembelian tabung yang dapat dilakukan pelanggan melalui email terdaftar.

4. Desain Sistem

Setelah menganalisa kebutuhan user dan membuat desain sistem dengan UML, dilakukan pembuatan desain sistem dengan pembuatan mockup. Mockup akan digunakan dalam mengimplementasikan user interface.

a. Login

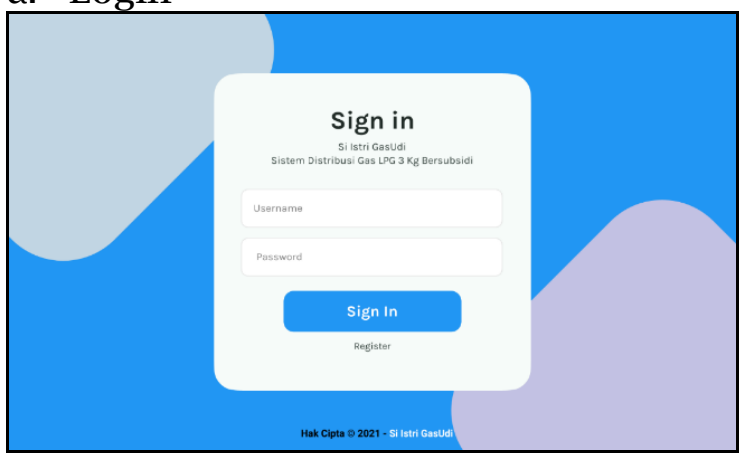

Gambar 3. Mockup halaman login agen dan pangkalan

b. Dashboard Pangkalan

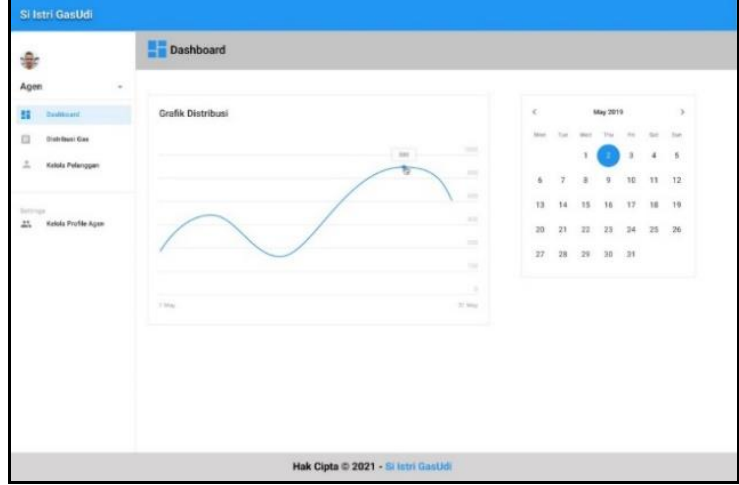

Gambar 4. Mockup halaman dashboard pangkalan 


\section{c. Kelola Pelangan}

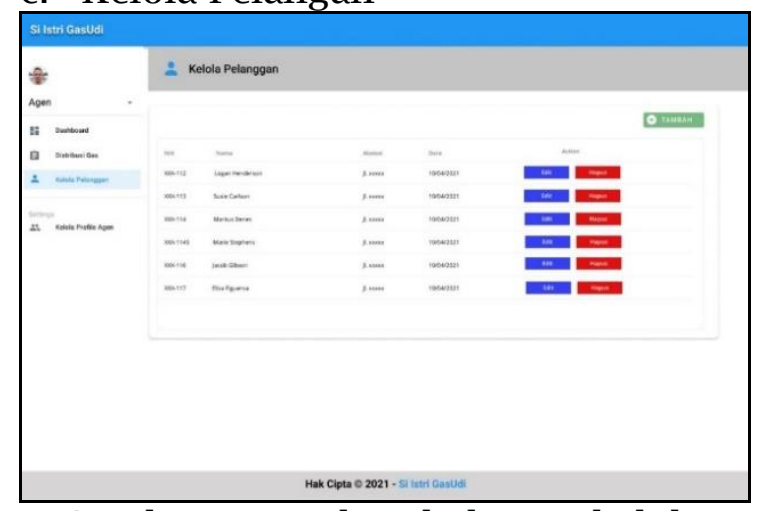

Gambar 5. Mockup halaman kelola

d. Distribusi Gas

$$
\text { pelanggan }
$$

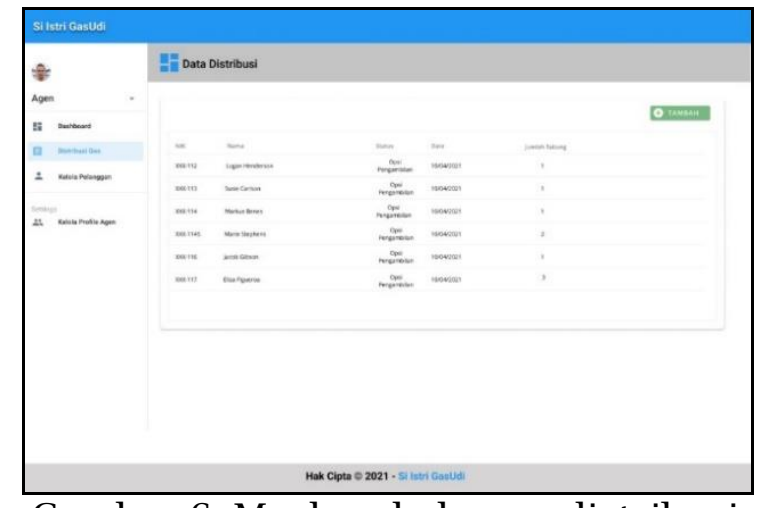

Gambar 6. Mockup halaman distribusi

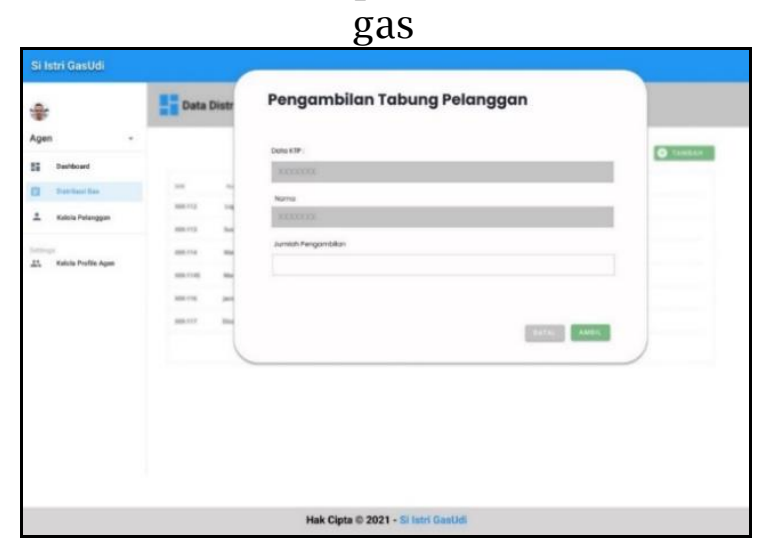

Gambar 7. Mockup halaman tambah distribusi gas

e. Dashboard Agen

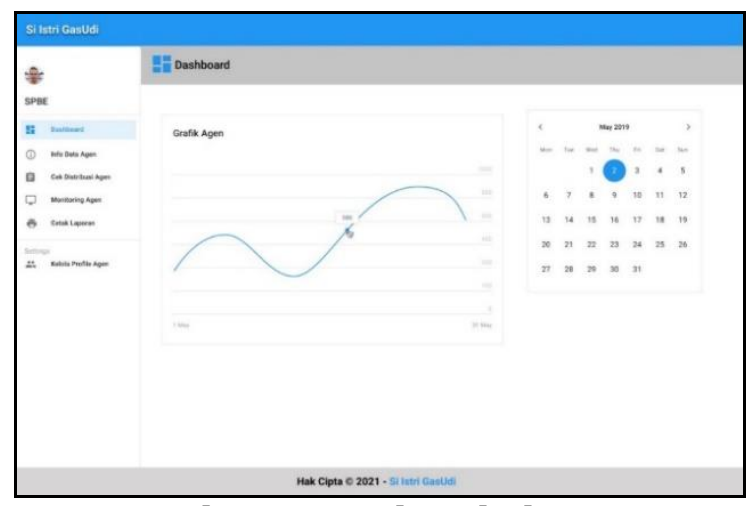

Gambar 8. Mockup halaman dashboard agen

f. Info Data Pangkalan

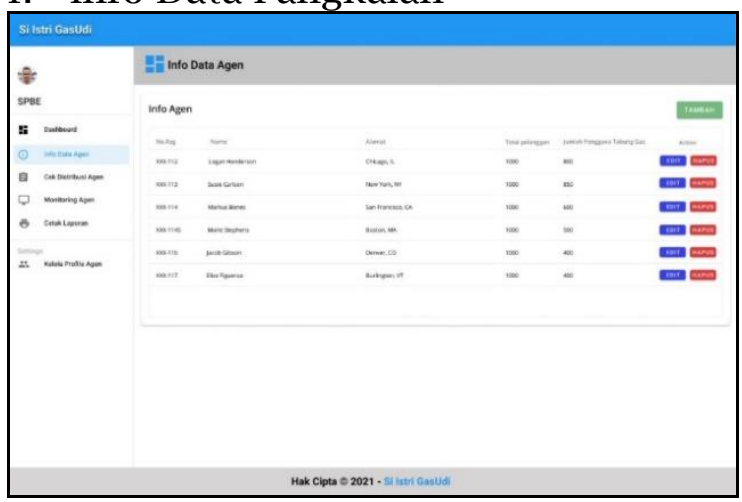

Gambar 9. Mockup halaman info data pangkalan

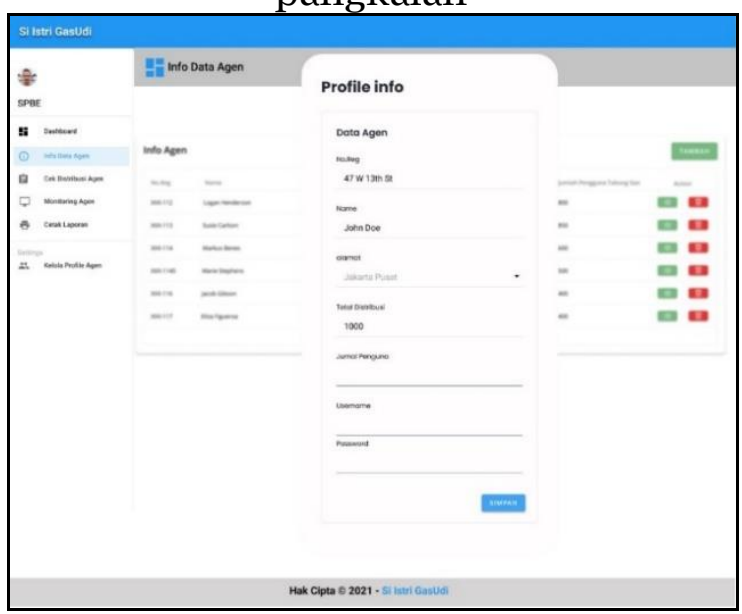

Gambar 10. Mockup halaman tambah info pangkalan

g. Cek Distribusi Pangkalan 


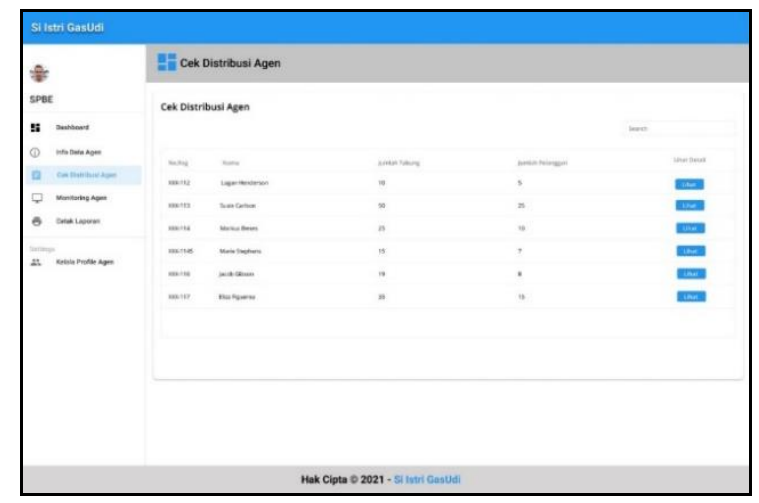

Gambar 11. Mockup halaman cek distribusi pangkalan

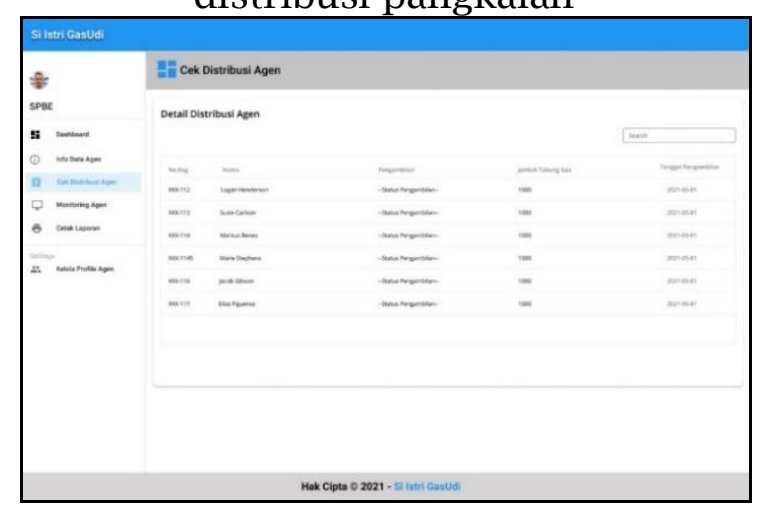

Gambar 12. Mockup halaman detail distribusi pangkalan

h. Monitoring Pangkalan

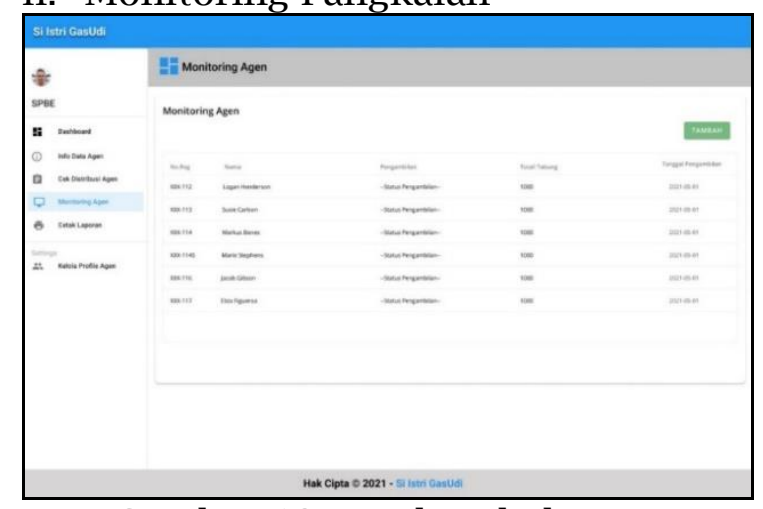

Gambar 13. Mockup halaman monitoring pangkalan

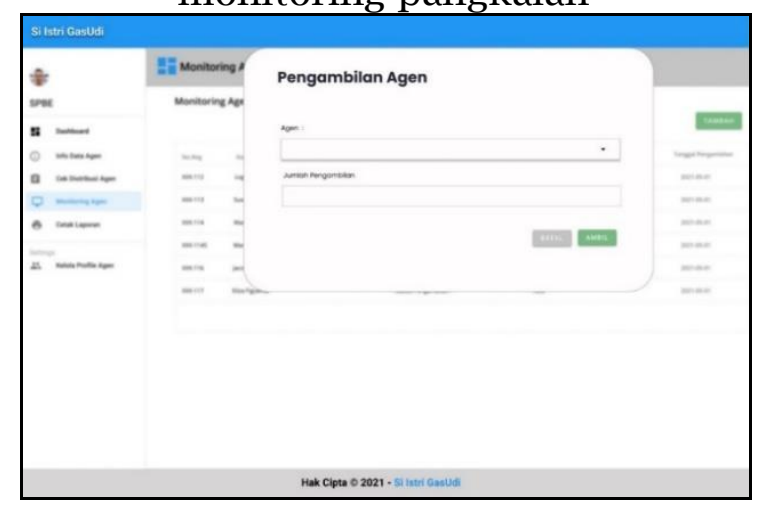

Gambar 14. Mockup halaman form pengambilan pangkalan

\section{i. Cetak Laporan}

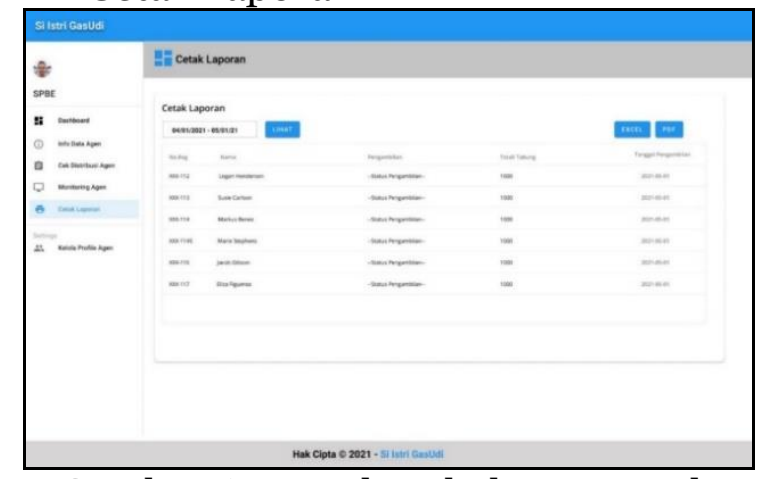

Gambar 15. Mockup halaman cetak laporan

j. Kelola Profile Agen

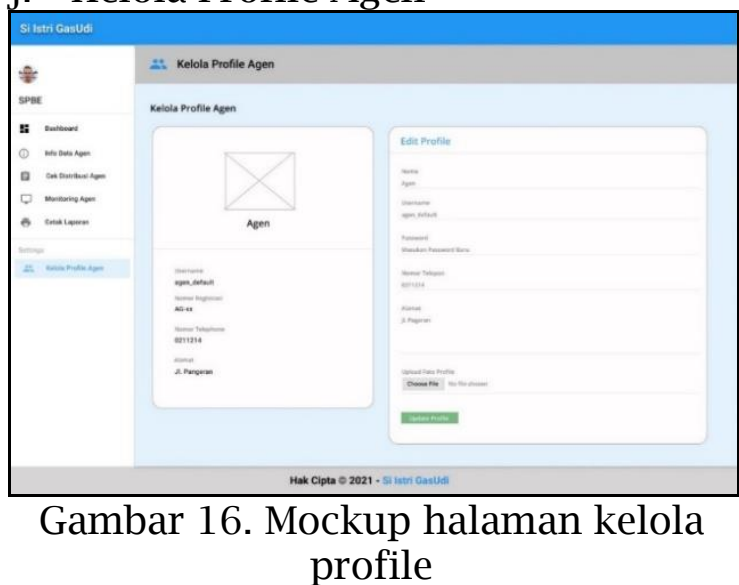

5. Implementasi User Interface

a. Sign In Agen dan Pangkalan

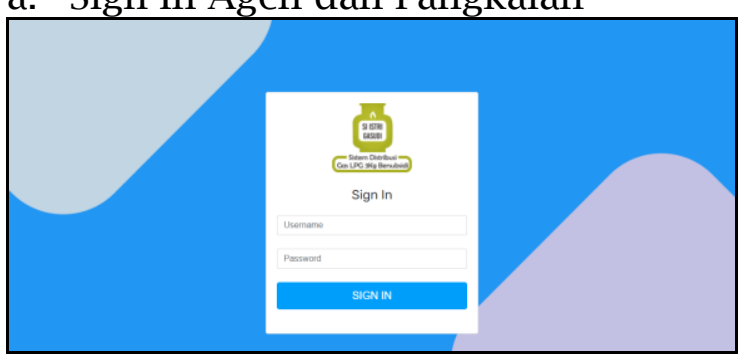

Gambar 17. Interface halaman sign in

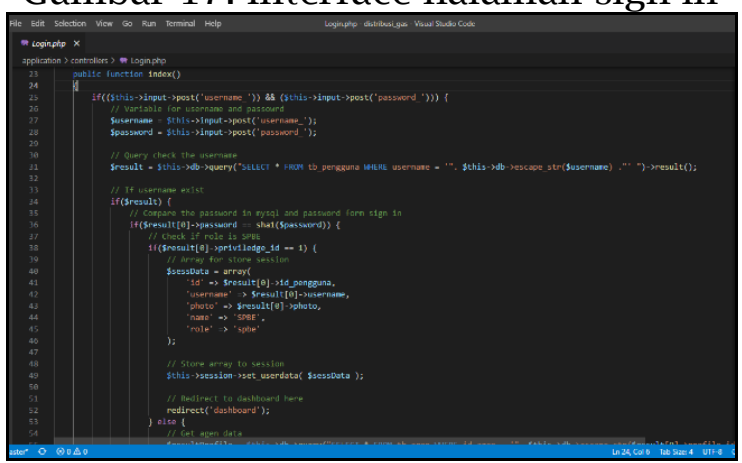

Gambar 18. Implementasi kode sign in b. Dashboard Pangkalan 


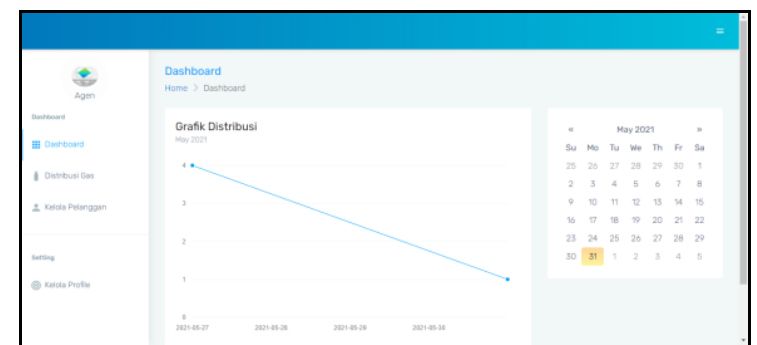

Gambar 19. Interface halaman dashboard pangkalan c. Kelola Pelanggan
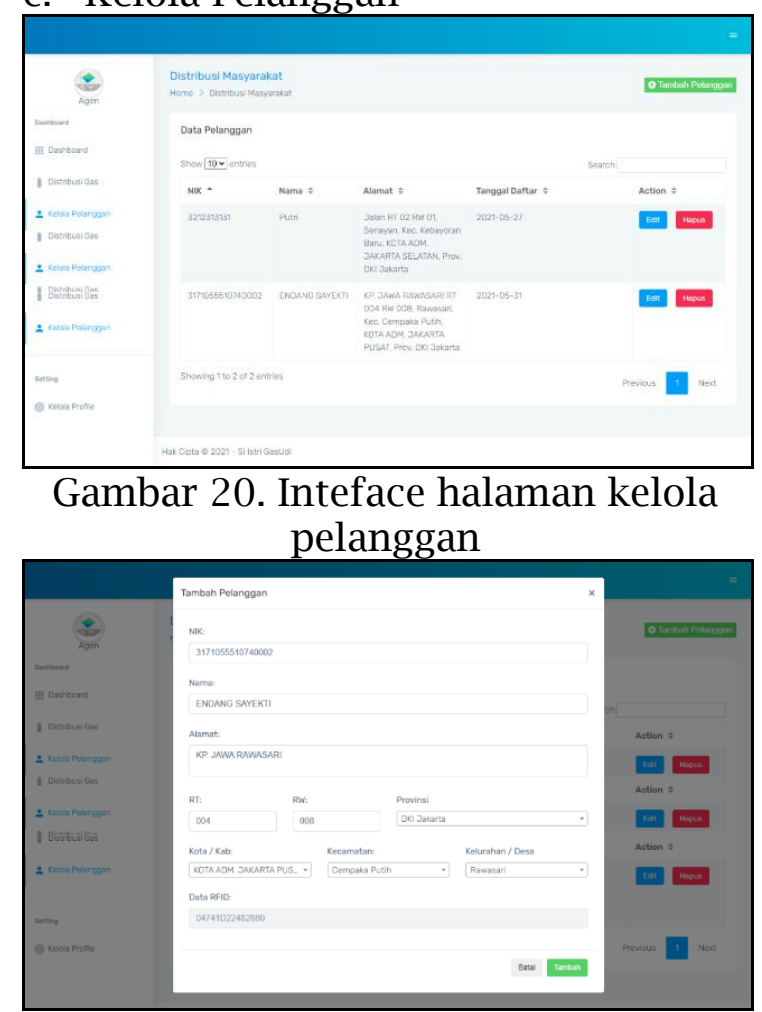

Gambar 21. Inteface halaman tambah pelanggan

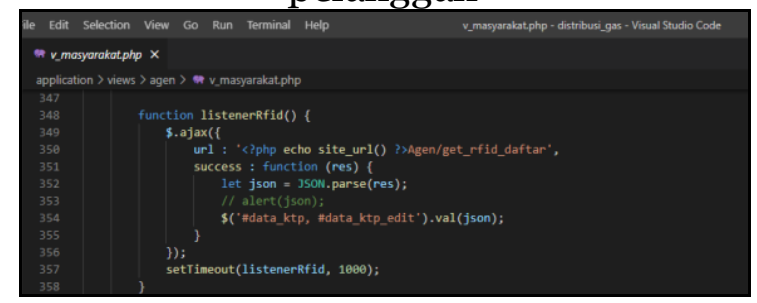

Gambar 22. Implementasi kode menunggu tapping E-KTP

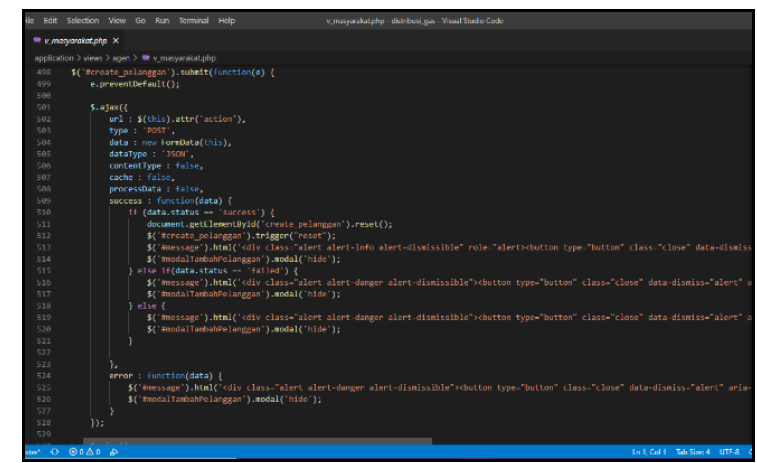

Gambar 23. Implementasi kode form tambah pelanggan

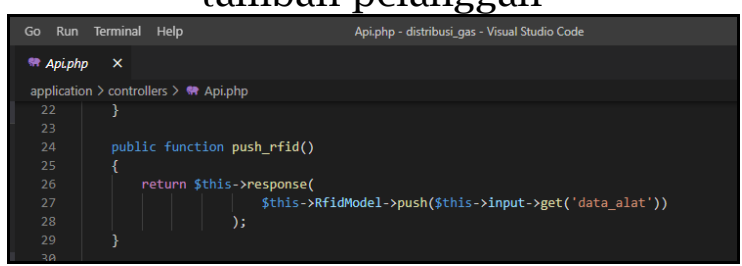

Gambar 24. Implementasi kode kirim data RFID

d. Distribusi Gas

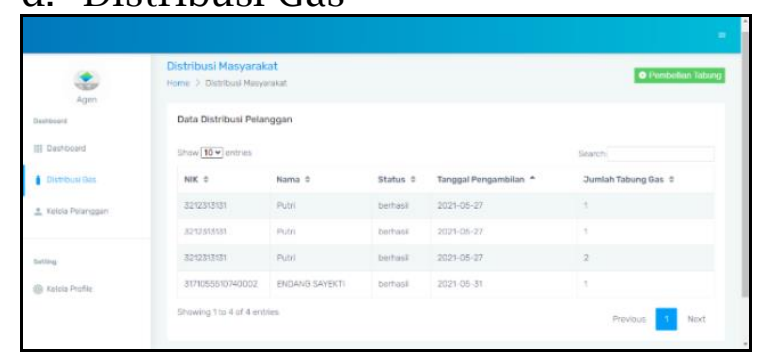

Gambar 25. Interface halaman distribusi gas

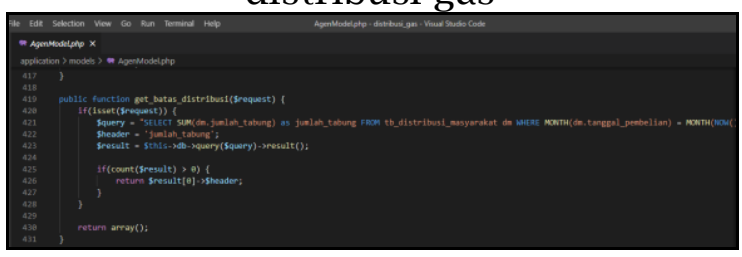

Gambar 26. Implementasi kode batas distribusi

e. Info Data Pangkalan

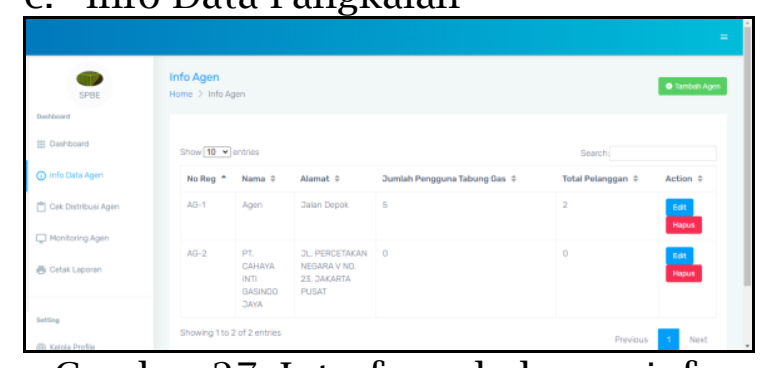

Gambar 27. Interfaces halaman info data pangkalan 


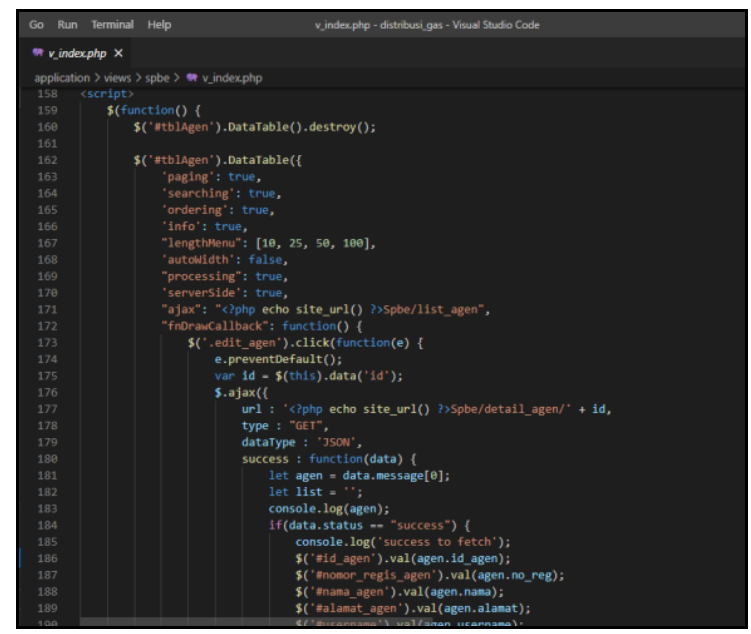

Gambar 28. Implementasi kode tabel data pangkalan dinamis

\section{Hasil}

Pengujian sistem ini menggunakan alpha testing dilakukan dengan metode black-box testing untuk menguji sistem, yang memiliki fungsionalitas sebagai user level agen dan pangkalan pada sistem monitoring distribusi gas LPG $3 \mathrm{Kg}$ menggunakan RFID pada E-KTP.

Table 1. Tabel halaman yang diuji pada agen

\begin{tabular}{lll}
\hline \multicolumn{1}{c}{ Item Uji } & \multicolumn{1}{c}{$\begin{array}{c}\text { Detail } \\
\text { Pengujian }\end{array}$} & $\begin{array}{c}\text { Jenis } \\
\text { Pengujian }\end{array}$ \\
\hline $\begin{array}{l}\text { Mutentikasi } \\
\text { di Web SI }\end{array}$ & $\begin{array}{l}\text { Melakukan } \\
\text { ISTRI }\end{array}$ & Black-Box In \\
GASUDI & Melakukan & \\
& Logout & Black-Box \\
& Melihat & \\
& grafik & \\
& pembelian & \\
Halaman & pangkalan & \\
Dashboard & (Jumlah & Black-Box \\
agen & tabung dan & \\
& tanggal & \\
& pembelian & \\
& pangkalan & \\
& pada agen) & \\
Halaman & Mengisi & \\
Info Data & semua field & Black-Box \\
Pangkalan & dalam form & \\
& tambah data &
\end{tabular}

pada agen pangkalan

Mengedit

semua field

dalam form

edit data

pangkalan

Menghapus

informasi

pangkalan

Black-Box

Black-Box

Halaman Melihat

Cek detail

Distribusi distribusi Black-Box

Pangkalan

pada agen

per

pangkalan

Memilih

nama

Halaman pangkalan

Monitoring

Pangkalan

pada agen

Membuat

jumlah

pengambilan

Black-Box

pangkalan

Mengisi field

kalender

Black-Box

Mendownloa

d laporan

pembelian

pangkalan

Halaman

dalam

Cetak

Laporan

pada agen

bentuk file

pdf

Mendownloa

d laporan

pembelian

pangkalan

dalam

bentuk file

excel

Mengedit

Halaman

semua field

dalam form

Black-Box

Kelola

Profile pada

agen

Black-Box

Black-Box

tar
Black-Box

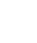

kelola profile

Mengupload

Foto

.


Setelah pengujian selesai dilakukan, langkah selanjutnya yaitu melakukan analisis data atau evaluasi sistem. Gunakan rumus berikut untuk menghitung persentase keberhasilan rata - rata :

Persentase keberhasilan $=\frac{\text { Jumlah item uji berhasil }}{\text { Jumlah seluruh item uji }} \times 100 \%$

Alpha testing pada sistem monitoring distribusi gas LPG $3 \mathrm{Kg}$ berbasis web mempunyai 45 skenario. Berikut adalah presentase keberhasilan dari alpha testing pada sistem:

alpha testing $=\frac{45}{45} \times 100 \%$

Berdasarkan hasil pengujian alpha yang dilakukan pada sistem, dapat disimpulkan bahwa pengujian alpha dilakukan dengan baik, karena semua fungsi yang diuji dapat berjalan sesuai dengan scenario yang diharapkan. Berdasarkan tingkat akurasi pada pengujian alpha, maka dapat disimpulkan bahwa sistem monitoring distribusi gas LPG $3 \mathrm{Kg}$ menggunakan RFID pada E-KTP berbasis web sudah bisa digunakan oleh agen dan pangkalan.

\section{Simpulan}

Dalam merancang bangun sisem distribusi gas LPG $3 \mathrm{Kg}$ menggunakan radio frequency identification (RFID) pada E-KTP berbasis web yang dikembangkan dengan metode SDLC model waterfall dapat dikatakan berhasil. Berdasarkan hasil analisis data dengan nilai seratus persen. Aplikasi ini dapat menjalankan fitur:

a. Agen dapat mengetahui informasiinformasi pangkalan yang melakukan pembelian pada agen dan membuatkan akun untuk pangkalan tersebut.

b. Agen dapat memonitoring distribusi gas LPG $3 \mathrm{Kg}$ yang dilakukan oleh pangkalanpangkalan yang terdaftar di agen.

c. Agen dapat mencatat setiap pembelian gas LPG $3 \mathrm{Kg}$ yang dilakukan oleh pangkalan terdaftar.

d. Agen dapat mencetak laporan pencatatan pembelian gas LPG $3 \mathrm{Kg}$ yang dilakukan oleh pangkalan yang telah terdaftar per bulan.

e. Pangkalan dapat menambahkan data pelanggan dengan cara mentapping E-KTP

f. Pangkalan dapat mencatat jumlah distribusi gas LPG $3 \mathrm{Kg}$ ke pelanggan dengan cara mentapping E-KTP.

g. Pangkalan dapat membatasi pembelian pelanggan sebanyak 4 kali selama sebulan untuk gas LPG $3 \mathrm{Kg}$ yang bersubsidi per individu.

Pengujian yang dilakukan pada sistem ini hanya dengan melakukan alpha testing.

\section{Referensi (Level II)}

CNBC Indonesia. (2020). CNBC Indonesia.

Juniardi Dermawan, S. H. (2017). IMPLEMENTASI MODEL WATERFALL PADA PENGEMBANGAN SISTEM INFORMASI PERHITUNGAN NILAI MATA PELAJARAN BERBASIS WEB PADA SEKOLAH DASAR ALAZHAR SYIFA BUDI JATIBENING. Notes and Queries, 19, 6. https://doi.org/10.1093/nq/s5VII.159.37-a

Mahesa, A. T., Rahmawan, H., Rinharsah, A., \& Arifin, S. (2019). Sistem Keamanan Brankas Berbasis Kartu Rfid E-Ktp. Jurnal Teknologi Dan Manajemen Informatika, 5(1). https://doi.org/10.26905/jtmi.v5i 1.3105

Pertamina. (2020). LPG $3 \mathrm{Kg}$ 